\title{
CLINICA DE DOENÇAS TROPICAIS E INFECCIOSAS: ESPECIALIDADE MÉDICA OU CONCEITUAÇÃO UNIVERSITÁRIA?
}

Nas escolas médicas do Brasil é habitual, rotineiro e tradicional o ensino de Clinica de Doenças Tropicais e Infecciosas. A matéria lecionada recebe essa denominação quando, na verdade, os aspectos con siderados dizem respeito a doenças transmissíveis. $O$. rótulo clássico, no entanto, tem sido mantido, apesar das impropirielades que encerra e, bàsicamente, representadas por dois fatos: a) os processos infecciosos são extremamente numerosos e nem sempre transmissiveis; b) poucas afecções realmente podem ser encaradas como estritamente tropicais, pois essa qualificação é aplicável a limitado número le piroblemas médicos, tais como, por exemplo, à doença de Jorge Lôbo, à doença de Carrión e à doença do sono.

No território brasileiro, processos transmissiveis são muito comuns e as mais expressivas endemias aí vigentes estão entre êles, bastando citar, para corroborar essa afirmação, a esquistossomíase mansônica, a doença de Chagas, a bouba, a amebiase, a ancilostomíase e outras helmintiases intestinais, a malária e as leishmanioses. Dessa maneira, o prccedimento dos dirigentes das Faculdades de Medicina do Brasil afigura-se plenamente correto e justificado e a conduta inicialmente lembra1a, relativa à ministração de conhecimer:tos pertinentes às doenças transmissívei., ó lógica, oportuna e realista.

Apesar dessa situação, precisamos resonhecer que o assunto, scb o ponto de vista conceitual, encontra-se à espera de zcrveniente apreciação. $A$ necessidade de definir Clínica de Doenças Tropicais e Infecciosas, ou Clínica de Drenças Transmissiveis, como verdadeira especialidade no âmbito da Medicina ou como mero arranjo universitário, com intuito de melhor estruturação didática, tem implicações não apenas acadêmicas, mas também, o que constitui questão mais importante, de ordem prática. Encarando o problema sob tal prisma, julgamos oportuno registrar as presentes considerações, capazes, possive!mente, de induzirem a deliberações construtivas.

Como decorrência da situação atual, alguns fatos, a seguir assinalados, são vigentes e demonstram a necessidade de uma definitiva caracterização.

1 - Nas Faculdades de Medicina to Brasil, o ensino de Clínica de Doenças Tropicais e Infecciosas tem lugar através de Cátedras, Departamentos ou Discipiinas de acôrdo com opinióes e interêsses pessoais e, até mesmo, de meros caprichos. $E$ fácil compreender que de estruturações tão diversas resultam rendimentos científicos e didáticos extremamente variáveis e heterogêneos.

2 - Em concursos para provimento de cargos públicos não universitários ou para composição de corpos clínicos de diferentes instituições, não existem habi. tualmente referências especificas à Clíniza de Doenças Tropicais e Infecciosas e 
supomos que os responsáveis pelas normas que regerão as escolhas julgam que diagnóstico e tratamento de doenças transmissiveis poderão, indiferentemente e sempre com bom rendimento, ficar a cargo de especialistas de vários tipos.

3 - Na especificação fornecida pela Associação Médica Brasileira para os cantidatos à obtenção de títulos de especialistas, não é feita qualquer menção à Clinica te Doenças Tropicais e Infecciosas. Só uma consulta a essa entidade poderá talvez esclarecer se essa circunstância decorre de atitude intencional ou de simples descuido relativo à questão.

4 - Os pouquíssimos médicos que, sm suas atividades profissionais privadas, ledicam-se exclusivamente à Clínica de Doenças Tropicais e Infecciosas, de ma neira habitual enfrentam condições que só em pequenas percentagens de casos sucedem com relação a diferentes especialilades; em outras palavras, rotineira e conumente devem prestar assistência a médicos e seus familiares ou a pacientes acometidos de doenças que encerram exzepcionais dificuldades pertinentes aos respectivos reconhecimentos etiológicos cu zos métodos terapêuticos.

5 - Clínica de Doenças Tropicais e Infecciosas, em muitas Faculdades de $M e-$ dicina, é ensinada por médicos que, em suas funções privadas ou tarefas de pesquisas, preocupam-se intensa e quase que integralmente com as mais diversas especialidades, as quais, freqüentemente, mantêm sòmente tênues relações com as doenças transmissiveis.

As especificações contidas nesses vá rios itens destacaram reais e concretos acontecimentos, motivadores de análises iudiciosas e de convenientes ponderaçöes. Em suma, destacaram condiçóes que, abordadas de formas mais definidas, estruty- radas e conscientes, certamente conduzi. riam a elogiáveis progressas e, pelo menos, a soluções mais uniformes e condizentes com as realidades didática, científica $e$ orática.

Presentemente, pelo menos no Brasil, Clinica de Doenças Tropicais e Infecciosas não é matéria, mesmo no âmbito universitário, interpretada de maneira uniforme, o que, sem dúvida, causa inconvenientes sob múltiplos aspectos, relativos, por exemplo, à qualidade e intensidade do ansino ministrado, ao desenvolvimento de pesquisas, ao despertar de vocações e à formação de eficientes e dedicados grupos de profissionais interessados. Com maior razão sob o ponto de vista da prática médica cotidiana, não houve sôbre a questão qualquer definição, mesmo introdutória ou incipiente.

Diante do exposto, fica patente a necessidade de dar ao problema um rumo mais claro, através de equilibrado equacionamento. Estas considerações não pretendem, assim sendo, ter mérito diferente taquele representado pela abordagem inizial do assunto, à procura de uma solução e conseqüente aprimoramento.

Serão, evidentemente, valiosas as manifestações, a propósito, de entidades como a Sociedade Brasileira de Medicina Tropical, destinadas a prestigiar tudo o que diz respeito ao ensino e pesquisa no campo das doenças transmissíveis. Ao mesmo tempo, as figuras exponenciais $1 i$. gadas a tais questões, e que estão em condições de agirem como lideres, poderão provocar o estabelecimento de pontos te vista definidos e capazes de levarem 3o aprimoramento da situação atual.

\section{Vicente Amato Neto *}

Nora oo Eutrow: O Editorial assinado por Vicente Amato Neto foi publicado no no 4, vol. 1; por haver ocorrido erros que comprometeram a exatidão do texto, julgou-se por hem republicá-lo na integra.

(*) Livre-docente de Clinica de Doenças Tropicais e Infectuosas, da Faculdade de Medicina da Cniversidade de São Paulo. Médico-chefe do Servico Doencas Transmissíycis do Hospital do Sorvidor Píblico Estadual do São Pablo. 